\title{
RISK ASSESSMENT OF THE WHOLE-BODY VIBRATION EXPOSURE FOR DRIVERS OF ARMORED VEHICLES: A CASE STUDY
}

\author{
G. ALFARO DEGAN ${ }^{1}$, G. COLTRINARI ${ }^{1}$, D. LIPPIELLO $^{1} \&$ M. PINZARI ${ }^{1}$ \\ ${ }^{1}$ Department of Engineering, University of Roma Tre, Rome, Italy.
}

\begin{abstract}
It is widely recognized in the field of safety at workplace that professional exposure to whole-body vibration (WBV) may generate unfavorable effects on workers' health. Among many involved categories, professional drivers are clearly one of the most exposed groups, as exposure time may last for the whole working period. This research is based on the results of measurements gathered from 14 subjects who drove vehicles for urban use. In particular, in order to highlight the effects of vehicle armoring on professional WBV dose, two sampling campaigns were carried out. In the first case, a car for standard use was used while, in the second one, another vehicle of the same model was modified with the installation of the armor-plate for ballistic protection. The assessment was carried out in accordance with ISO 2631-1(97), under the same boundary conditions, and finally the daily exposure parameter was assessed. Furthermore, to allow a comparison independent of individual factors, the exposed subjects were divided into homogeneous groups of different classes based on their body weight and height. The results obtained showed that WBV exposure is clearly connected with vehicle characteristics. In particular, the installation of bulletproof armor, contributing to a change in the car mass distribution and its total weight, determines a generalized reduction of professional dose. This reduction may be quantified in a range from $10 \%$ to $20 \%$ depending on the individual characteristics of the driver.
\end{abstract}

Keywords: armored vehicles, whole-body vibration, worker exposure.

\section{INTRODUCTION}

The biodynamic response to whole-body vibration (WBV) has been examined since the 1950s. All passengers and drivers that use any vehicle are often exposed to a risk of WBV with unfavorable effects on the body and health due to vibrations and mechanical shocks. Moreover, when the use of vehicles is connected with professional reasons, the exposure time to WBV tends to grow and may last for the whole working day [1]. In such conditions, any parameter affecting the driver's exposure assumes a significant role. In particular, the characteristics of the human biodynamic response of seated occupants have been shown to be influenced by several factors [2], such as the type of seat [3], body posture [4], body weight and height [5], and the type and the amplitude of the vibrational excitation [6]. These last factors probably represent the most important parameters [7, 8]. Moreover, exposure to WBV may generate relevant effects such as discomfort and also some progressive degenerative changes of the lumbar spine [9], gastric motility [10] rather than low back pain [11].

In order to protect the comfort of workers and their health, the most effective approach to manage this phenomenon, is by risk assessment. This procedure may be performed with different methodologies, [12]: analytical methods [13] and sampling campaigns. These 
campaigns consist of measurements carried out in accordance with ISO 2631(1997). This norm requires to calculate the parameter $\mathrm{A}(8)$ which takes into account the equivalent acceleration that is calculated along three axes of a standard reference system, and the daily exposure time of the worker. It is recognized that the evaluation of exposure is very complex due to the uncertainty of the response of the human body to a given vibrational source [14] as well as its non-linearity [15]. Furthermore, several physical and individual factors may influence the results of field measurements. The position of the seat and the type of backrest play an important role but other factors such as the condition of soil [16], the vehicle speed [17], the driving style, the vehicle characteristics, and operative conditions also generate relevant consequences [18]. In the use of particular vehicles like tractors, WBV is dependent upon the nature of the operation performed [19] and it is influenced by the use of four-wheel drive [20], by the eccentricity of the tire that changes the amplitude of the solicitation [21], speed conditions, and structural characteristics [22]. Similar problems were observed among bus drivers, [23] whereas the drivers of loaders and dumpers are exposed to a relevant dose of WBV because of the vibrations associated with the operations of loading and hauling [24], with the use of tires with chains and with terrain type [25]. As described above, the structural characteristics of the vehicle influence the exposure to WBV of the drivers.

This study is aimed at investigating the influence of inertial characteristics of the vehicle on the worker's exposure when the structure of the chassis is changed by the addition of bulletproof armor. This installation is generally realized on wheeled and tracked military terrain vehicles but it has also become more common among urban employment cars for police patrol activities.

\section{MATERIAL AND METHODS}

To highlight the influence of the mass distribution and total weight of the same model of vehicle on WBV, two sampling campaigns were realized under the same boundary conditions. In the first campaign, 14 subjects were asked to drive on a predefined route with a standard car for urban use. In the second campaign, the same group of workers used the same car model modified by the addition of bulletproof materials for ballistic protection. During each test, the frequency-weighted acceleration was recorded. Then the daily dose was assessed and finally the two sets of data were compared. The exposure assessment was carried out according to the specifications established by the ISO 2631-1 (97).

\subsection{Risk assessment procedure}

All evaluations of WBV exposure and the acceleration data have been measured and analyzed in terms of ISO 2631-1 (97). The daily exposure to WBV for a seated worker is assessed as the equivalent continuous root mean squared (RMS) acceleration over an eight-hour period, as shown below:

$$
A_{8}=\bar{a}_{w} \sqrt{\frac{T_{\text {exp }}}{8}}
$$

where:

$A_{8}$ is the daily dose expressed as $\left[\mathrm{m} / \mathrm{s}^{2}\right]$

$T_{\text {exp }}$ is the exposure time expressed as [hour]

$a_{w}$ is the equivalent continuous RMS acceleration also expressed as $\left[\mathrm{m} / \mathrm{s}^{2}\right]$. 
The frequency-weighted acceleration values in the fore and aft direction (x-axis), lateral direction (y-axis), and vertical direction (z-axis) on the seat were weighted. $W_{k}$ and $W_{d}$, as defined in ISO 2631-1(97), were adopted for the frequency weightings for vertical and horizontal signals, respectively. In particular, $a_{w}$ is defined as follows:

$$
a_{w}=\max \left(K_{x} a_{w x}, K_{y} a_{w y}, K_{z} a_{w z}\right)
$$

Scaling factors for the determination of health for seated workers exposure have been applied ( $\mathrm{x}$-axis, $k=1.4$; $\mathrm{y}$-axis, $k=1.4$; $\mathrm{z}$-axis, $k=1.0$ ). The $\mathrm{K}$ factors are specific weighted coefficient to take into account the non-linearity of human response to different vibration frequencies. The ISO 2631-1(97) standard states that the frequency-weighted RMS is defined from the range of maximum human sensitivity: for frequencies between 0.5 and $2 \mathrm{~Hz}$ for the $\mathrm{x}$ and $\mathrm{y}$ axes, and between 4 and $8 \mathrm{~Hz}$ for the $\mathrm{z}$ axis (the relative axe to vertical vibration). The highest frequency-weighted acceleration value was selected for the comparison with the threshold limit value proposed by ISO 2631-1(97). This last specifies the set of K factors to be utilized in each case because, in a more general case, when for a given vehicle the daily activity is composed of different working phases (such as driving along paved roads rather than along urban streets with different characteristics), each phase may be characterized with a different dominant axis and different maximum acceleration components. Each value is recorded and the final parameter is obtained as follows:

$$
A_{8}=\sqrt{\frac{\sum_{i=1}^{N} a_{w, i}^{2} T_{i}}{8}}
$$

where:

$a_{w, i}$ represents the dominant component of the equivalent RMS acceleration for the $i$ - th working phase and

$T_{i}$, the exposure duration for the same phase.

Finally, the $A_{8}$ parameter, obtained according to (1) or (3), is compared with values imposed by norm. If any worker has been exposed to WBV for 8 hours a day, the norm ISO 2631-1(97) provides three guidance health caution zones: $\left(\mathrm{Av}<0.5 \mathrm{~m} / \mathrm{s}^{2}\right.$ : health effects have not been clearly documented; $0.5 \mathrm{~m} / \mathrm{s}^{2}<\mathrm{Av}<0.8 \mathrm{~m} / \mathrm{s}^{2}$ : caution with respect to potential health risk indicated; Av $>0.8 \mathrm{~m} / \mathrm{s}^{2}$ : health risk is likely).

\subsection{Sampling device}

In the measurement campaign, the data acquisition and post elaboration were carried out by means of a four-channel system. The simultaneous acquisition of data along different axes was carried out by means of four accelerometers. In particular, the first one (Uniaxial accelerometer PCB 393A03) was attached on both vehicles through a permanent magnet to a special iron bar fixed immediately adjacent to the passenger's seat (Fig. 1 on the left).

The aim of this measurement was to test whether the input signal could be considered as a constant and the vibration received at the seat base was repetitive for all subjects. Instead, the acceleration at the driver's seat was measured in the $\mathrm{x}, \mathrm{y}$, and $\mathrm{z}$-directions (fore-aft $=\mathrm{x}$-axis; lateral $=\mathrm{y}$-axis; vertical $=\mathrm{z}$-axis) with remaining three channels using a tri-axial accelerometer (Tri-axial accelerometer SEN027-PCB) fixed to seat center through an adhesive ribbon (Fig. 1 on the right). All data were acquired with a sampling frequency of 5,000 $\mathrm{Hz}$ using Samurai software. The meter was programmed to calculate the Vibration Dose Values (VDVs) 

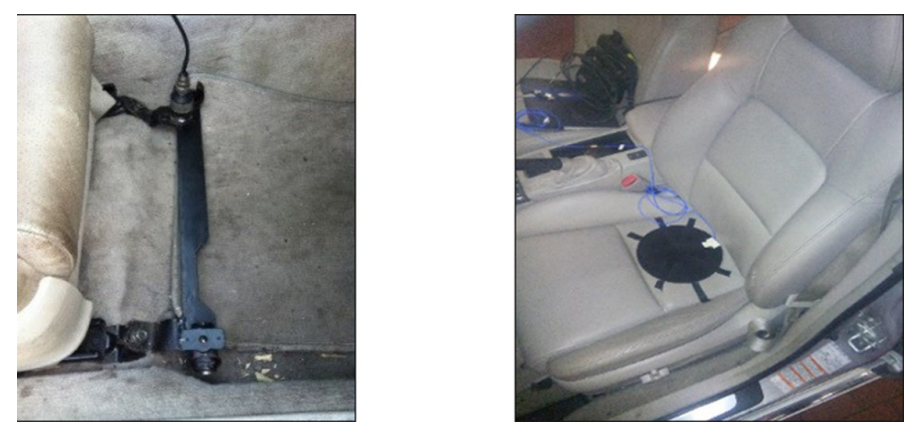

Figure 1: Transducer positioning on special iron bar (figure on the left) and on driver's seat (figure on the right).

Table 1: Model, positioning, and sensitivity of sampling devices.

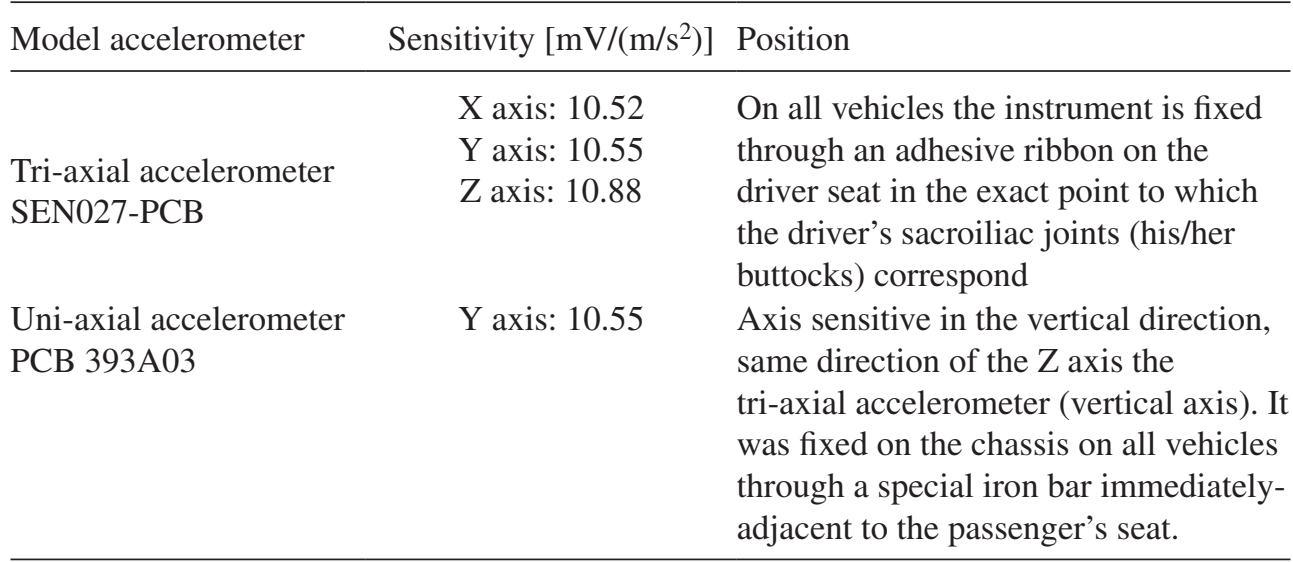

in table 1 the characteristics of the accelerometers are summarized using Noise Vibration Work software according to the frequency-weighting filters defined by the UNI 2631-1(97).

\subsection{Field study}

The measurement campaign was realized using two cars for urban use. In the first campaign, a car for standard use was used while in the second one another vehicle of the same model modified with the installation of the armor-plate for ballistic protection was used as shown in Fig. 2.

A manual transmission system with cruise control was installed in both models. As shown, the two models differ from each other because of the addition of the bulletproof armor, so in terms of total weight, there was a difference of more than $200 \mathrm{~kg}$ together with a variation of mass distribution (Table 2).

This difference implies an alteration of the vibrational signal. In both phases of the sampling campaigns, the runs were completed only with the driver and one researcher for data collection. The sampled acceleration was found unaffected by the weight of the driver, and thus it was considered that there were no input errors owing to any variation in the physical 

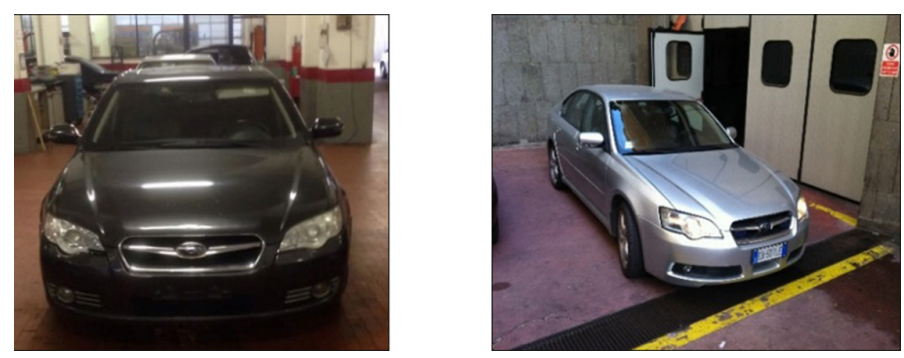

Figure 2: Armored model vehicle on the left and the standard one on the right.

Table 2: Characteristics of vehicles.

\begin{tabular}{lccc}
\hline Model vehicle & Year & Weight & $\mathrm{km}$ \\
\hline $\begin{array}{l}\text { Subaru legacy } \\
\text { standard model }\end{array}$ & 2008 & 1.60 tonnes & $160.000 \mathrm{~km}$ \\
$\begin{array}{l}\text { Subaru legacy } \\
\text { armored model }\end{array}$ & 2009 & 1.82 tonnes & $161.500 \mathrm{~km}$ \\
\hline
\end{tabular}

Table 3: Source signal characteristics.

\begin{tabular}{lcc}
\hline Vehicle & $\begin{array}{c}\text { Acceleration arithmetic } \\
\text { mean }\left(\mathrm{m} / \mathrm{s}^{2}\right)\end{array}$ & $\begin{array}{c}\text { Standard deviation } \\
\left(\mathrm{m} / \mathrm{s}^{2}\right)\end{array}$ \\
\hline Standard car model & 0.38 & 0.009 \\
Armored car model & 0.51 & 0.016 \\
\hline
\end{tabular}

configuration of system car-driver-device. Table 3 shows, for each vehicle, the measured mean value of the sampled acceleration and its standard deviation.

This study measures the WBV exposure of 14 drivers while driving on a $4.5 \mathrm{~km}$ urban road with paved surfaces (Fig. 3). The speed of the vehicle was constant during the test and fixed at $45 \mathrm{~km} / \mathrm{h}$. Each test was undertaken during the same time slot (11:00-14:00 a.m.) to ensure traffic repeatable conditions.

All subjects who participated in the experiment were male with different physical characteristics and variable age. The mean age of the participants was 45 (range 24-66 years), the mean height of the subjects was $177.43 \mathrm{~cm}$ (range165-190 cm), and the mean weight of the subjects was $80.2 \mathrm{~kg}$ (range $67.3-102.4 \mathrm{~kg}$ ). Before conducting the experiment, the purpose of this study was explained to all subjects and they were allowed to control to the seat location to obtain a natural driving position. Each field test lasted for three minutes and each sample was repeated five times. Thus it was possible to calculate an arithmetical mean for each of the three axis measurement according to the following relationships:

$$
\overline{a_{W, i}}=\frac{\sum_{j=1}^{5} a_{W, j}}{5}
$$



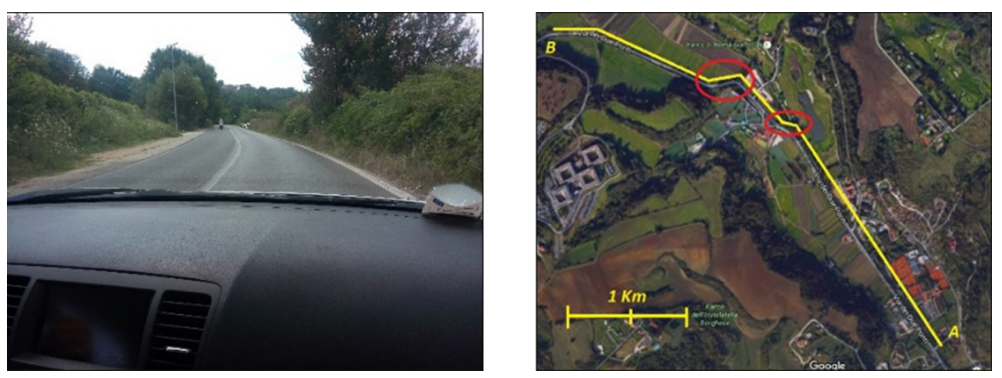

Figure 3: Urban paved road (figure on left) and characteristics of route on the right (red circles indicate curves).

\section{RESULTS}

The two sampling campaigns allowed to collect 28 tests and to obtain 14 complete WBV measurements for standard and armored vehicles. The following graphs show, expressed in terms of $a_{w}$, the max value obtained along each of three axes of the reference system standard, for the first campaign (standard vehicle) as shown in Fig. 4.

In any case, the predominant direction of WBV exposures was the z-axis. The same trend may be observed in the second campaign (armored vehicle) as shown in Fig. 5.

In order to characterize the source signal, a specific function was calculated. This was obtained for each time interval of $125 \mathrm{~ms}$, as the mean $a_{w z}$ value, among the 14 samples. Figure 6 compares the two average functions referred to the standard and armored vehicle.

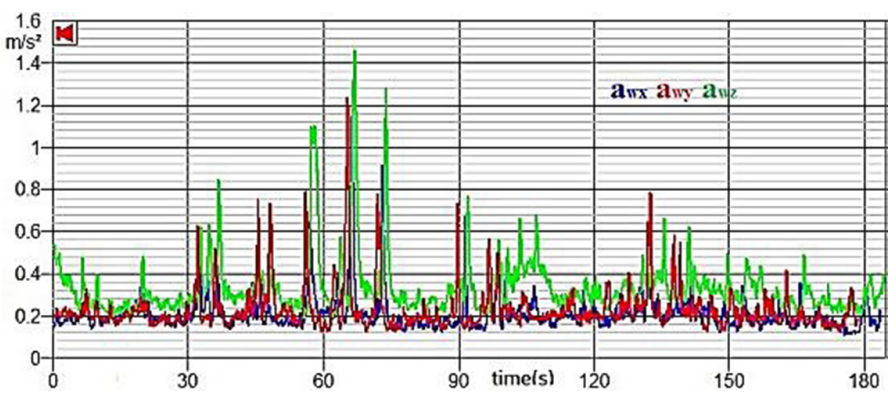

Figure 4: Signal along three axes of standard vehicle.

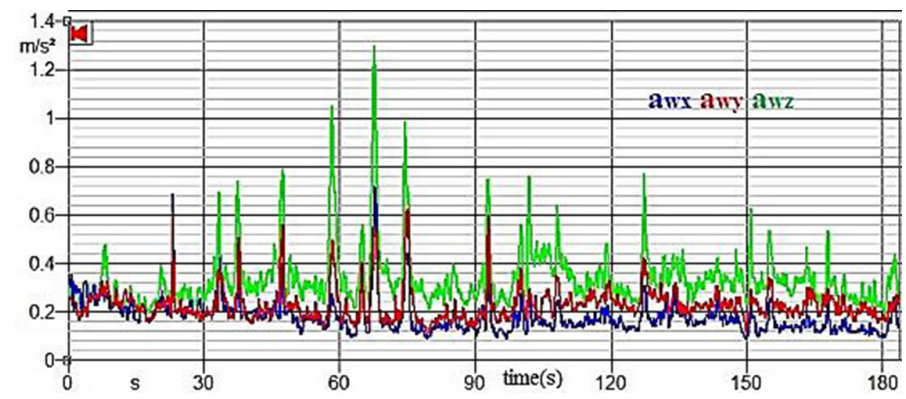

Figure 5: Signal along three axes of armored vehicle. 


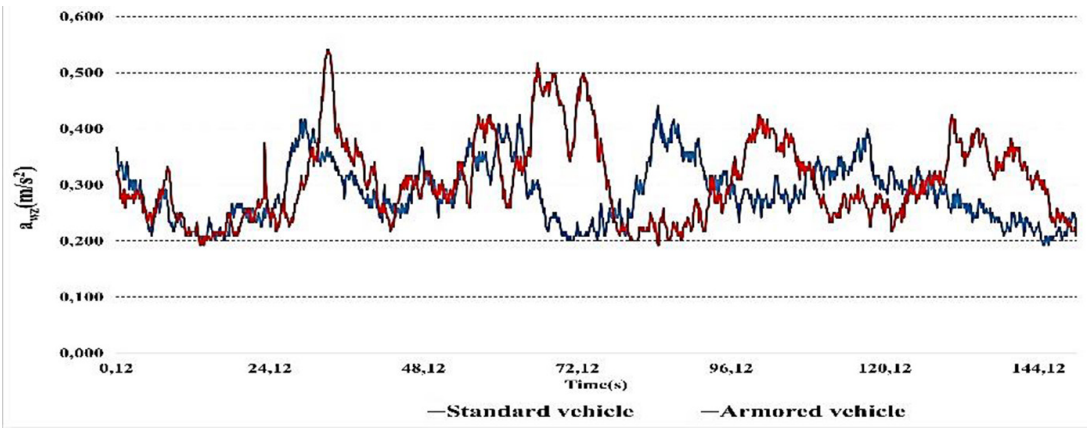

Figure 6: Comparison between standard and armored vehicle.

The two sets of data indicated that the drivers in armored vehicles were exposed to the highest discomfort levels of vertical vibration as compared to those on standard vehicles.

\section{DISCUSSION}

The data collected in Table 4 allow to highlight the anthropometric characteristics of subjects and relative values of $\mathrm{A}(8)$. Columns on the left show the body characteristics (weight, height, and age) of each driver while those on the right highlight the different values of $\mathrm{A}(8)$ between the standard and armored vehicle. In the last column the difference between the two sets of data is highlighted through percentage values.

On the basis of sampled data, it is possible to observe a significant correlation between exposure to WBV and installation of bulletproof armor on the chassis. In particular, the dose referred to armored vehicles decreases from a minimum value of $10,09 \%$ (driver 3 ) to a max value of $11,48 \%$ (driver 9). These results seem to underline a possible correlation between the

Table 4: $\mathrm{A}(8)$ data recorded for standard and armored vehicle.

\begin{tabular}{lcccccc}
\hline Driver & $\begin{array}{c}\text { Weight } \\
{[\mathrm{kg}]}\end{array}$ & $\begin{array}{c}\text { Height } \\
{[\mathrm{cm}]}\end{array}$ & Age & $\begin{array}{c}\text { A(8) Standard } \\
\text { vehicle }\end{array}$ & $\begin{array}{c}\text { A(8) Armored } \\
\text { vehicle }\end{array}$ & $\Delta \%$ \\
\hline 1 & 88 & 182 & 24 & 0,288 & 0,255 & $-11,48$ \\
2 & 88 & 182 & 24 & 0,282 & 0,248 & $-12,06$ \\
3 & 71 & 168 & 52 & 0,293 & 0,263 & $-10,09$ \\
4 & 74 & 170 & 47 & 0,285 & 0,250 & $-12,46$ \\
5 & 84 & 183 & 59 & 0,318 & 0,269 & $-15,41$ \\
6 & 86 & 184 & 40 & 0,295 & 0,262 & $-11,19$ \\
7 & 70 & 165 & 65 & 0,294 & 0,257 & $-12,61$ \\
8 & 72 & 168 & 55 & 0,299 & 0,265 & $-11,22$ \\
9 & 102 & 174 & 50 & 0,290 & 0,236 & $-18,48$ \\
10 & 67 & 165 & 56 & 0,292 & 0,259 & $-11,47$ \\
11 & 79 & 190 & 28 & 0,300 & 0,246 & $-18,03$ \\
12 & 79 & 190 & 28 & 0,294 & 0,260 & $-11,56$ \\
13 & 68 & 175 & 66 & 0,296 & 0,265 & $-10,47$ \\
14 & 92 & 188 & 36 & 0,288 & 0,253 & $-12,33$ \\
\hline
\end{tabular}




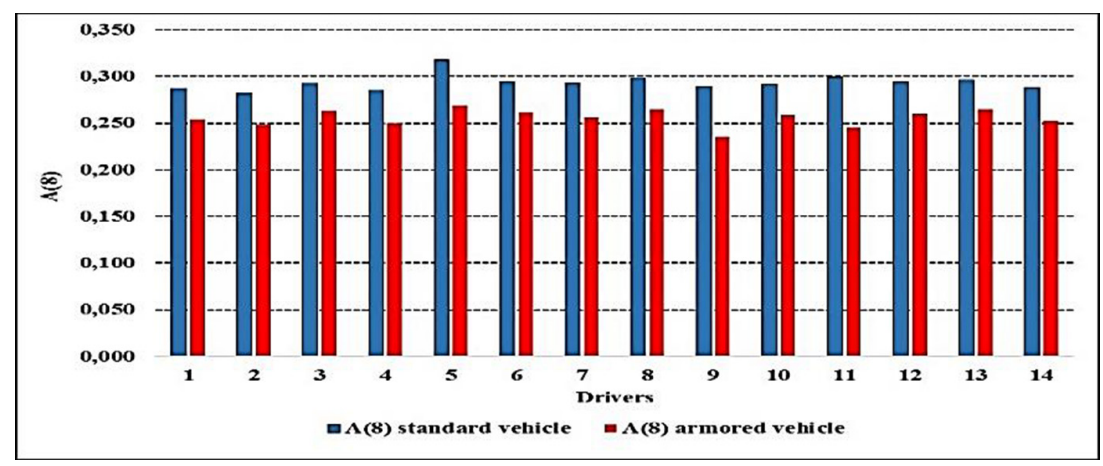

Figure 7: Trend of $\mathrm{A}(8)$ for standard and armored vehicle.

body weight of the driver and the WBV dose itself. In particular, the highest percentage reduction is observed for the heaviest driver $\left(n^{\circ} 9\right)$ as shown in Fig. 7.

\section{CONCLUSION}

The analysis of sampled data was carried out with the same approach and all field tests were realized under the same boundary conditions. Data from the campaigns were analyzed to highlight the effects of installation of bulletproof armor. The algorithms for calculating the WBV exposure parameters were performed using a Noise Vibration Work software. The WBV exposure parameters were calculated for each driver in accordance with ISO 2631-1(97). In particular, the WBV exposure was calculated from the weighted RMS vibration $\left(a_{w}\right)$, which was assessed for an 8-hour daily value $(\mathrm{A}(8))$. The data obtained from the measurement campaigns showed a variation in the WBV exposure values due to the addition of an armor-plate. It is shown clearly that two different parameters affect this phenomenon: the mass characteristics of the vehicle and the anthropometric factors of the exposed subjects. The differences between WBV data referred to standard and armored vehicles showed that the installation of bulletproof armor contributes to a change in the car mass distribution and its total weight. In other words, taking into account the same vehicle model, characterized with a different total weight, it was possible to point out that the values of $\mathrm{a}_{\mathrm{w}}$ show a reduction all over the frequency spectrum. This fact has generated attenuation of WBV exposures and has determined a generalized reduction of professional dose in a range from $10 \%$ to $20 \%$. Although the number of samples is reduced, this result may be considered as a general one. Furthermore, another interesting outcome was the different reduction of $\mathrm{A}(8)$ between subjects depending on their individual characteristics and therefore the percent variation of $\mathrm{A}(8)$ is always different among all drivers. In spite of the limited number of samples, the results strongly encourage further research. In future studies a larger number of samples will help to better characterize the effect of the chassis modification on the exposure to WBV. The aim of future works may be the estimate of an empiric formulation that may allow to predict the WBV dose, under certain boundary conditions, for subjects on board different vehicles.

\section{REFERENCES}

[1] Paddan, G.S. \& Griffin, M.J., Effect of seating on exposures to whole-body vibration in vehicles. Journal of Sound and Vibration, 253(1), pp. 215-241, 2002.

http://dx.doi.org/10.1006/jsvi.2001.4257 
[2] Rakheja, S., Dong, R.G., Patra, S., Boileau, P.É., Marcotte, P. \& Warren, C., Biodynamics of the human body under whole-body vibration: Synthesis of the reported data. International Journal of Industrial Ergonomics, 40, pp. 710-732, 2010. http://dx.doi.org/10.1016/j.ergon.2010.06.005

[3] Lewis, C.H. \& Griffin, M.J., Evaluating the vibration isolation of soft seat cushions using an active anthropodynamic dummy. Journal of Sound and Vibration, 253(1), pp. 295-311, 2002. http://dx.doi.org/10.1006/jsvi.2001.4261

[4] Paddan, G.S., Mansfield, N.J., Arrowsmith, C.I., Rimell, A.N., King, S.K. \& Holmes, S.R., The influence of seat backrest angle on perceived discomfort during exposure to vertical whole-body vibration. Ergonomics, 55(8), pp. 923-936, 2012. http://dx.doi.org/10.1080/00140139.2012.684889

[5] Alfaro Degan, G., Lippiello, D. \& Pinzari, M. Whole body vibrations: experimental assessment of anthropometric differences on the effects of WBV exposure in quarry workers. WIT Transactions on the Built Environment, 151, pp. 61-72, 2015. ISSN: 1743-3509, doi: 10.2495/SAFE150061. http://dx.doi.org/10.2495/SAFE150061

[6] Beard, G.F. \& Griffin, M.J., Discomfort caused by low-frequency lateral oscillation, roll oscillation and roll-compensated lateral oscillation. Ergonomics, 56(1), pp. 103-114, 2013. http://dx.doi.org/10.1080/00140139.2012.729613

[7] Fairley, T.E. \& Griffin, M.J., The apparent mass of the seated human body: vertical vibration. Journal of Biomechanics, 22, pp. 81-94, 1989. http://dx.doi.org/10.1016/0021-9290(89)90031-6

[8] Paddan, G.S. \& Griffin, M.J., A review of the transmission of translational seat vibration to the head. Journal of Sound and Vibration, 215, pp. 863-882, 1998. http://dx.doi.org/10.1006/jsvi.1998.1592

[9] Seidel, H., Bluthner, R., Hinz, B. \& Schust, M., On the health risk of the lumbar spine due to whole-body vibration theoretical approach, experimental data and evaluation of whole-body vibration. Journal of Sound and Vibration, 215(4), pp. 723-741, 1998. http://dx.doi.org/10.1006/jsvi.1998.1601

[10] Ishitake, T., Miyazaki, Y., Noguchi, R., Ando, H. \& Matoba, T., Evaluation of frequency weighting (iso 2631-1) for acute effects of whole-body vibration on gastric motility. Journal of Sound and Vibration, 253(1), pp. 31-36, 2002. http://dx.doi.org/10.1006/jsvi.2001.4263

[11] Bovenzia, M., Ruia, F., Negroa, C., D’Agostina, F., Angotzi, G., Ianchi, S., Bramanti, L., Festa, G., Gatti, S., Pinto, I., Rondina, L. \& Stacchini, N., An epidemiological study of low back pain in professional drivers. Journal of Sound and Vibration, 298, pp. 514-539, 2006. http://dx.doi.org/10.1016/j.jsv.2006.06.001

[12] Griffin, M.J., A comparison of standardized methods for predicting the hazards of whole-body vibration and repeated shocks. Journal of Sound and Vibration, 215(4), pp. 883-914, 1998.

http://dx.doi.org/10.1006/jsvi.1998.1600

[13] Alfaro Degan, G, Lippiello, D., Lorenzetti, S. \& Pinzari, M., Vibration assessing models: comparison between methods. WIT Transactions on Biomedicine and Health, 16, pp. 59-69, 2013. ISSN: 1743-3525, doi: 10.2495/EHR130061.

http://dx.doi.org/10.2495/EHR130061 
[14] Mansfield, N.J. \& Griffin, M.J., Effects of posture and vibration magnitude on apparent mass and pelvis rotation during exposure to whole-body vertical vibration. Journal of Sound and Vibration, 253(1), pp. 93-107, 2002. http://dx.doi.org/10.1006/jsvi.2001.4251

[15] Nawayseh, N. \& Griffin, M.J., Tri-axial forces at the seat and backrest during wholebody vertical vibration. Journal of Sound and Vibration, 277, pp. 309-326, 2004. http://dx.doi.org/10.1016/j.jsv.2003.09.048

[16] Tiemessen, I.J., Hulshof, C.T.J. \& Frings-Dresen, M.H.W., An overview of strategies to reduce whole-body vibration exposure on drivers: a systematic review. International Journal of Industrial Ergonomics, 37, pp. 245-256, 2007. http://dx.doi.org/10.1016/j.ergon.2006.10.021

[17] Khorshid, E., Alkalby, F. \& Kamal, H., Measurement of whole-body vibration exposure from speed control humps. Journal of Sound and Vibration, 304, pp. 640-659, 2007. http://dx.doi.org/10.1016/j.jsv.2007.03.013

[18] Gallais, L. \& Griffin, M.J., Low back pain in car drivers: a review of studies published 1975 to 2005. Journal of Sound and Vibration, 298, pp. 499-513, 2006. http://dx.doi.org/10.1016/j.jsv.2006.06.012

[19] Scarlett, A.J., Price, J.S. \& Stayner, R.M., Whole-body vibration: Evaluation of emission and exposure levels arising from agricultural tractors. Journal of Terramechanics, 44, pp. 65-73, 2007. http://dx.doi.org/10.1016/j.jterra.2006.01.006

[20] Langer, T.H., Ebbesen, M.K. \& Kordestani, A., Experimental analysis of occupational whole-body vibration exposure of agricultural tractor with large square baler. International Journal of Industrial Ergonomics, 47, pp. 79-83, 2015. http://dx.doi.org/10.1016/j.ergon.2015.02.009

[21] Cutini, M., Romano, E. \& Bisaglia, C., Assessment of the influence of the eccentricity of tires on the whole-body vibration of tractor drivers during transport on asphalt roads. Journal of Terramechanics, 49, pp. 197-206, 2012. http://dx.doi.org/10.1016/j.jterra.2012.05.004

[22] Tsujimura, H., Taoda, K. \& Kitahara, T., A field study of exposure to whole-body vibration due to agricultural machines in a full-time rice farmer over one year. Journal of Occupational Health, 57, pp. 378-387, 2015. http://dx.doi.org/10.1539/joh.14-0260-OA

[23] Okunribido, O.O., Shimbles, S.J. \& Magnusson, M., City bus driving and low back pain: a study of the exposures to posture demands, manual materials handling and whole-body vibration. Applied Ergonomics, 38, pp. 29-38, 2007.

http://dx.doi.org/10.1016/j.apergo.2006.01.006

[24] Rehna, B., Lundstrom, R., Nilsson, L., Liljelind, I. \& Jarvholm, B., Variation in exposure to whole-body vibration for operators of forwarder vehicles-aspects on measurement strategies and prevention. International Journal of Industrial Ergonomics, 35, pp. 831-842, 2005.

http://dx.doi.org/10.1016/j.ergon.2005.03.001

[25] Blood, R.P., Rynell, P.W. \& Johnson, P.W., Whole-body vibration in heavy equipment operators of a front-end loader: Role of task exposure and tire configuration with and without traction chains. Journal of Safety Research, 43, pp. 357-364, 2012. http://dx.doi.org/10.1016/j.jsr.2012.10.006 